\title{
QUANTIFICAÇÃO DA CHUVA OCULTA NA SERRA DO MAR, ESTADO DO RIO DE
} JANEIRO

\section{QUANTIFICATION OF THE HIDDEN RAIN IN SERRA DO MAR, STATE OF RIO DE JANEIRO}

\author{
Carlos Rodrigues Pereira ${ }^{1}$ Ricardo Valcarcel ${ }^{2}$ Rafael Silva Barbosa ${ }^{3}$
}

\begin{abstract}
RESUMO
As florestas de altitude situadas nas microbacias da Serra do Mar, no Estado do Rio de Janeiro, apresentam serviços ambientais que contribuem para os diversos segmentos da sociedade carioca que demandam água de qualidade e quantidade, assim como ambientes sustentáveis. A condensação do vapor d'água nas copas das árvores é um desses serviços, pois contribui positivamente para o balanço hídrico. Seu entendimento poderá auxiliar no equacionamento de soluções e planejamento ambiental sustentável. Esta percepção/ compreensão motivou o estudo da interceptação horizontal $(\mathrm{IH})$ em área montanhosa na região de Nova Friburgo - RJ. Foram coletados e analisados dados de precipitação total (PT), precipitação pluviométrica ou externa (P), IH, precipitação interna (PI) e interceptação da copa (IC) no período compreendido entre dezembro de 2003 e janeiro de 2004, na encosta a barlavento da Serra do Mar, em Nova Friburgo. Os valores de precipitação total (PT) e Interceptação Horizontal (IH) corresponderam a 786,23 mm e 68,71 mm, respectivamente. As perdas por IC foram de $25,46 \%$ e a PT foi de $125,66 \%$ em relação à P, evidenciando que a IH influenciou no balanço hídrico da região constituindo-se num importante serviço ambiental para os ecossistemas e para a população dependente da bacia estudada.
\end{abstract}

Palavras-chave: precipitação; interceptação; balanço hídrico; precipitação interna.

\begin{abstract}
The Montane Forest situated at the watersheds of Serra do Mar, state of Rio de Janeiro, presents environmental services that contribute for diverse segments of society, which demands water in quantity and with quality, as well as sustainable environments. Water vapor condensation at forest canopies is one of these services, as it contributes positively with hydrological water balance. It's understanding can help the equation of solutions on sustainable environment planning, which motivated the study of horizontal interception (IH) on a Mountainous area in Nova Friburgo region. It was collected and analyzed data from total rainfall (PT), pluviometric rainfall (P), IH, internal precipitation (PI) e canopy interception (IC) during December 2003 to January 2004, at the windward slope of Serra do Mar, in Nova Friburgo. Values for total rainfall (PT) and horizontal interception (IH) corresponded to $786.23 \mathrm{~mm}$ and $68,71 \mathrm{~mm}$, respectively. The lost from IC where of $25.46 \%$ and PT was $125.66 \%$ in relation to P, showing that IH influenced on the regional hydrological balance, constituting an important environmental service for ecosystem and population who depends on the watershed studied.
\end{abstract}

Keywords: precipitation; interception; hydrological balance; Intern precipitation.

1 Engenheiro Agrônomo, Dr., Professor Associado II do Departamento de Engenharia Agrícola e Meio Ambiente, Escola de Engenharia, Universidade Federal Fluminense, Rua Passo da Pátria, 156, São Domingos, CEP 24210-240, Niterói (RJ), Brasil. crpereira@vm.uff.br

2 Engenheiro Florestal, Dr., Professor Associado IV do Departamento de Ciências Ambientais, Universidade Federal Rural do Rio de Janeiro, Rodovia BR 465, Km 7, CEP 23561-000, Seropédica (RJ), Brasil. ricardo.valcarcel@gmail.com

3 Engenheiro Florestal, MSc., Rua Conde de Baependi, 112/408, Flamengo, CEP 22231-140, Rio de Janeiro (RJ), Brasil.rafael.florestall@gmail.com

Recebido para publicação em 15/11/2011 e aceito em 13/04/2015 


\section{INTRODUÇ̃̃O}

As florestas nas encostas de microbacias contribuem para a dinâmica da precipitação pluviométrica e conformação dos seus balanços hídricos (MOLCHANOV, 1971; ARONICA; CANNAROZZO, 2000; CHEN; CHEN, 2005; GANDOLFI et al., 2007; GIGLIO; KOBIYAMA, 2013) e com isso se beneficiam em mecanismos de manutenção e de regeneração natural (SCCOTI et al., 2011).

A parcela da chuva interceptada pela copa (IC) representa a quantidade de chuva que regressa à atmosfera sem atingir o solo, ou seja, que evapora da superfície vegetal (LIMA, 1986), significando uma forma de perda de água no balanço hídrico da microbacia. O dossel reduz a intensidade da energia cinética das gotas de chuva, contribui para aporte de matéria orgânica, que afeta a estruturação dos solos e melhora as condições de infiltração da água no solo, favorecendo a recarga do lençol freático, entre outros serviços ambientais prestados.

O dossel pode interferir na condensação do vapor d'água nas florestas de altitude, aumentando a interceptação horizontal (IH). Esse fenômeno, da $\mathrm{IH}$, ocorre em áreas cuja temperatura da superfície da cobertura vegetal atinge valores abaixo da temperatura do ponto de orvalho, ou quando intercepta gotículas em suspensão (VALCARCEL, 1982; GIGLIO; KOBIYAMA, 2013).

O orvalho tem especial significação para as coberturas florestais. De acordo com o clima e as características do ambiente físico, a produtividade do orvalho pode chegar a várias dezenas de milímetros ao ano. No Chile, painéis de captura de nevoeiro, com área de exposição igual a $100 \mathrm{~m}^{2}$ instalados no deserto do Atacama, chegaram a coletar de 100 a 1000 litros de água por dia, abastecendo pequenos grupos populacionais (OTTONI NETTO, 1993).

Às gotículas de água em suspensão na atmosfera, interceptadas pelo dossel, assim como ao vapor atmosférico condensado, mesmo nos dias de chuva, denomina-se chuva oculta.

Precipitação pluviométrica de baixa intensidade pode implicar em menor precipitação interna (precipitação sob o dossel) e, consequentemente, maior interceptação vertical das copas. A interceptação vertical está relacionada à intensidade da precipitação, ou seja, quanto maior a intensidade da chuva menor o percentual de chuva interceptado pelo dossel (LIMA, 1986; LLOYD et al. 1988; HUBER; OYARZÚN, 1992;
NALON; VELLARDI, 1993; CHEN; CHEN, 2005; GANDOLFI et al., 2007).

Percentualmente, o escoamento pelo tronco pode ser considerado de pouca importância quando comparado ao montante atingido pela precipitação interna (VALCARCEL, 1982; LLOYD et al., 1988; JOHNSON, 1990; ARCOVA et al., 2003; GANDOLFI et al., 2007; SHINZATO et al., 2011).

Ao estudar o balanço hídrico nos Andes Venezuelanos, Valcarcel (1982) observou que a vegetação proporcionou aumentos na quantidade de água para o sistema, principalmente em áreas de grande altitude, nas quais a floresta funciona como um condensador de umidade, aumentando a precipitação total.

Este trabalho teve como objetivo avaliar a influência da cobertura florestal, situada acima de 1.600 metros de altitude, em microbacias da Serra do Mar, sobre a chuva oculta.

\section{MATERIAL E MÉTODOS}

O experimento foi conduzido na Área de Proteção Ambiental do Pico do Caledônia, Parque Estadual dos Três Picos, município de Nova Friburgo - RJ, no verão de 2003/2004, durante os meses de dezembro e janeiro. A área localiza-se entre os Picos da Pedra K2 (1.750 m) e Caledônia $(2.252 \mathrm{~m})$, apresentando aproximadamente 300 ha, perímetro de $9,4 \mathrm{~km}$ e comprimento no sentido interflúvio/talvegue do rio Paraíba do Sul de 3,05 $\mathrm{km}$, entre as coordenadas geográficas $22^{\circ} 21^{\prime} 33^{\prime \prime}$ e 42 33 '54". Os divisores das bacias do rio Macacu (vertente Atlântica) e Bengala (bacia do rio Paraíba do Sul), na encosta da Serra do Mar, formam os limites da área estudada, com altitude mínima de $1600 \mathrm{~m}$.

A microbacia é de $2^{\mathrm{a}}$ ordem; índices de compacidade de 1,52; circularidade de 0,32; conformando aspecto alongado. O tempo de concentração é de 1:38:00 (uma hora e trinta e oito minutos) e de deflúvio médio mínimo anual de $20 \mathrm{l} / \mathrm{s}$.

O relevo é irregular formando uma paisagem declivosa, com cobertura florestal constituída de Floresta Ombrófila Densa Montana com transposição para campos de altitude (IBGE, 1992). As plântulas, epífitas e lianas são abundantes, assim como, a ocorrência de bambus e palmeiras (LIMA; GUEDES-BRUNI, 1997; SANSEVERO et al., 2011).

Um conjunto de interceptadores 
(pluviômetro Ville de Paris, dotado de haletas (Figura 1)) composto de quatro unidades, coletou a precipitação total (PT), composta pela interceptação horizontal $(\mathrm{IH})$ mais a chuva (P). Servindo de testemunha, a precipitação externa ou precipitação pluviométrica (P) foi medida, nas bordas da área experimental, utilizando-se quatro pluviômetros tipo Ville de Paris, instalados em locais abertos, distantes, aproximadamente, $50 \mathrm{~m}$ da área florestada.

Cada interceptador, com haletas de 1.033,2 $\mathrm{cm}^{2}(\mathrm{~A})$ de área total e reservatório $(\mathrm{H})$, captou a chuva que incidiu diretamente sobre sua superfície de captação (chuva); o volume de vapor de água em deslocamento lateral, condensando a partir do choque dessa massa de ar úmido com a área das haletas e as microgotículas suspensas na massa de ar, também interceptadas. A diferença entre os valores de precipitação pluviométrica, ou da média dos pluviômetros externos $(\mathrm{P})$ e dos pluviômetros com haletas (PT), em mililitros, foi dividida pela área total da haleta, gerando a interceptação horizontal (IH), em milímetros.

Os valores da precipitação abaixo do dossel (copa das árvores), ou precipitação interna (PI) foram obtidos da média das medidas realizadas com cinco grupos de pluviômetros (PL1, PL2, PL3, PL4 e PL5). Cada grupo foi composto por um conjunto de 15 pluviômetros, os quais tinham um diâmetro de $8,3 \mathrm{~cm}$, fabricados de lata e dispostos em malha, distanciados seis metros entre si. Cada grupo foi instalado nas altitudes $1.605,1.620,1.630,1.640$ e 1.660 metros, respectivamente. As coletas foram realizadas diariamente às 9:00 h no período de $18 \mathrm{de}$ dezembro de 2003 a 17 de janeiro de 2004.

A IH foi obtida a partir da diferença entre a média dos volumes de chuva coletados nos interceptadores (PT) e nos pluviômetros externos (P), ou seja, $I H=P T-P$, em que IH é a interceptação horizontal $(\mathrm{mm})$, ou seja, gotículas interceptadas mais vapor d'água condensado; PT é a precipitação total de chuva (mm) coletada pelos interceptadores, ou seja, precipitação pluviométrica, mais gotículas interceptadas, mais vapor d'água condensado; P é a precipitação pluviométrica $(\mathrm{mm})$, coletada pelos pluviômetros testemunha, ou seja, precipitação pluviométrica fora da área florestada.

A interceptação da copa (IC) foi obtida a partir da diferença entre os valores de chuva observados fora e dentro da floresta, ou seja, $I C=P-P I$, em que IC é a interceptação pela copa das árvores (mm); P é a precipitação pluviométrica (mm); PI é a precipitação interna $(\mathrm{mm})$.

Os valores do escoamento pelo tronco foram negligenciados, uma vez que são muito pequenos em relação às outras componentes.

Os valores de PT e P, apresentados neste
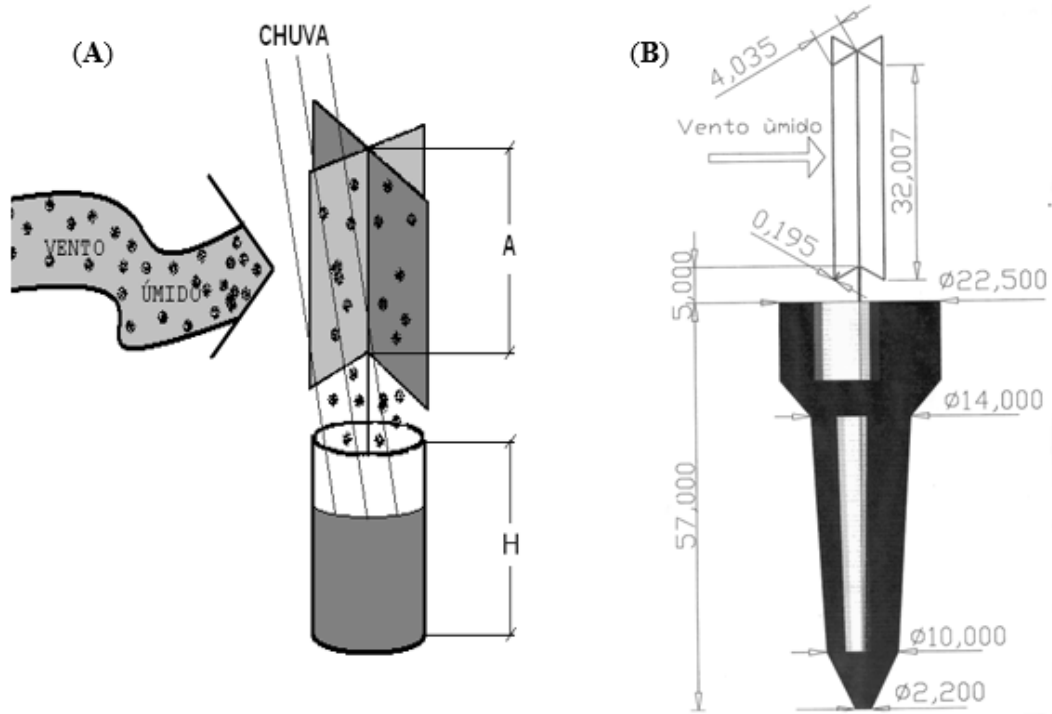

FIGURA 1: Detalhes do interceptador usado para coleta da precipitação total (PT) (pluviômetro Ville de Paris, dotado de interceptador); (A) croqui do sistema de coleta, (B) dimensões originais do instrumento $(\mathrm{cm})$.

FIGURE 1: Details of the interceptor used for precipitation survey (PT) (pluviometer Ville de Paris, with interceptor); (A) Sketch of the survey system, (B) Original dimensions of the equipment (cm). 
trabalho, foram obtidos das médias das leituras dos conjuntos instalados em campo.

\section{RESULTADOS E DISCUSSÃO}

Os dados coletados neste estudo indicaram uma importante informação acerca da função da condensação do vapor d'água, ou chuva oculta, como componente dos serviços ambientais das florestas da Serra do Mar, no Estado do Rio de Janeiro (Figuras 2A, 2B e 2C), discutidos detalhadamente a seguir.

A interceptação horizontal e a precipitação externa (Figuras 2A, 2B e 3A) apresentaram baixa correlação com a temperatura média (Figura $3 \mathrm{~B}$ ), demonstrando que o teor de umidade do ar foi o fator de influência mais importante para essa componente. A Figura $2 \mathrm{C}$ permite visualizar, nos períodos com baixa precipitação externa, que a interceptação horizontal teve correlação positiva com a temperatura, ou seja, nos períodos com baixa temperatura, menores foram os valores de percentagem da interceptação horizontal, indicando a influência da concentração de umidade do ar.

A precipitação interna correlacionou-se com a altitude (Figura 3C) demonstrando a influência de temperaturas menores, devidas à altitude, sobre a condensação.

A precipitação interna (PI) apresentou correlação positiva com a precipitação externa, ao passo que a interceptação de copa (IC) foi praticamente sem tendência com relação à precipitação externa.

À medida que a altitude aumentou, de PL1 a PL5, os valores negativos de IC também aumentaram, mostrando que houve uma condensação crescente com a altitude. Os resultados de IC negativos são oriundos da condensação das massas de ar úmido que resultaram em eventos de precipitação interna, mesmo durante os períodos entre os intervalos de chuva (Figuras 4 a 8 ). Contemplando os fundamentos ecológicos, tais como regulação, suporte e produção (PRIMAVESI; PRIMAVESI, 2003), os ecossistemas em sua evolução buscam cada vez mais equilíbrio e sintonia de suas funções sistêmicas, em uma dinâmica funcional do ecossistema em relação ao uso do recurso água na forma de vapor. Esta dinâmica tende a aumentar a disponibilidade de água, na forma líquida, no ambiente.

De forma geral, os valores de precipitação interna foram maiores sob o dossel das florestas, mostrando valores crescentes com o aumento da precipitação externa (Figura 9). Resultados semelhantes foram observados por Lima (1986) que constatou valores de quantidade de água na precipitação interna e na interceptação pelas copas com alta correlação com o tipo de vegetação e com as condições de tempo locais.

Em 77,42\% do período analisado, os valores médios da precipitação interna, em todos os pontos avaliados, foram superiores à precipitação externa, mostrando a contribuição da chuva oculta para a recarga dos aquíferos destas regiões situadas nas cabeceiras das bacias hidrográficas.

As chuvas ou a precipitação pluviométrica medida fora da área florestada (P) apresentaram valores médios de $25,36 \mathrm{~mm} \cdot \mathrm{dia}^{-1} \mathrm{e}$ a precipitação interna (PI) 31,87 mm.dia ${ }^{-1}$ (Tabela 1). Esses dados mostraram ainda que os valores de precipitação interna aumentam com a altitude. Levando em conta apenas os valores totais do período analisado, verificou-se que a interceptação pela copa (IC), resultado da diferença entre a precipitação externa $(\mathrm{P})$ e precipitação interna (PI), apresentou resultados positivos somente nos pluviômetros 1,2 e 3 (PL1, PL2, PL3). No PL1, verificou-se que foram interceptados pela copa (IC) $117,18 \mathrm{~mm}$, ou seja, $14,9 \%$ do total coletado, sendo esse o maior valor encontrado. Nos PL2 e PL3, os valores foram mais baixos, ou seja, 5,4\% e 8,8\% respectivamente. Esses resultados foram menores que aqueles observados por Valcarcel (1982), em que se observaram 19\% de interceptação possivelmente devido às diferenças morfológicas da vegetação; tais como, área de copa, altura das árvores (rugosidade), composição de espécies, etc.; entre os dois ambientes estudados.

Nas áreas com altitudes maiores, ou seja, 1640 m e 1660 m, os pluviômetros PL4 e PL5 coletaram valores de precipitação interna (PI) superior à precipitação externa (P). O PL4 coletou 976,2 mme o PL5 coletou 1.833,4 mm indicando a ocorrência de precipitação oculta, ou seja, a condensação de vapor d'água, quando o vento entrou em contato com a superfície da vegetação; e também a interceptação de gotículas em suspensão, essas somadas à chuva ocorrida resultaram nos valores superiores à precipitação externa em $24,2 \%$ e $133,2 \%$, respectivamente.

Por outro lado, analisando todos os dias do período de amostragem, foram observados valores negativos em todos os cinco setores de amostragem (Figuras 4, 5, 6, 7 e 8), os quais, somados individualmente foram $-59,33 ;-128,27$; $-69,86$; -229,92 e -1153,47 para os pluviômetros 
(A)

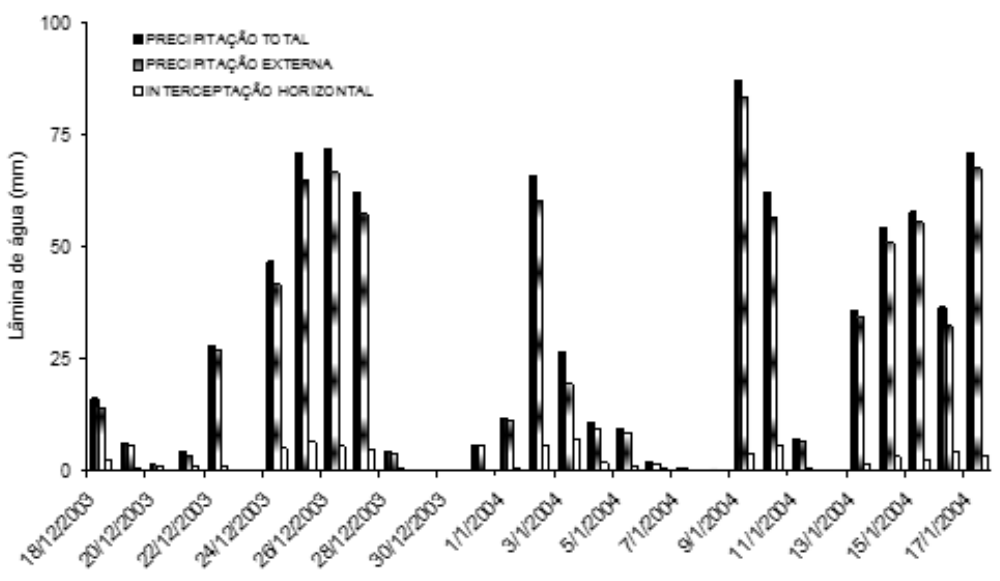

(B)

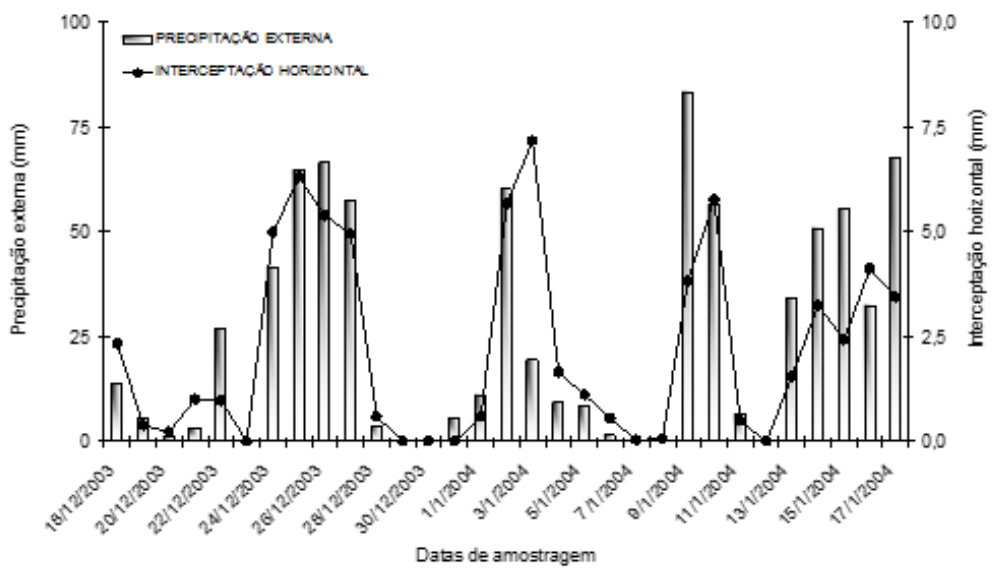

(C)

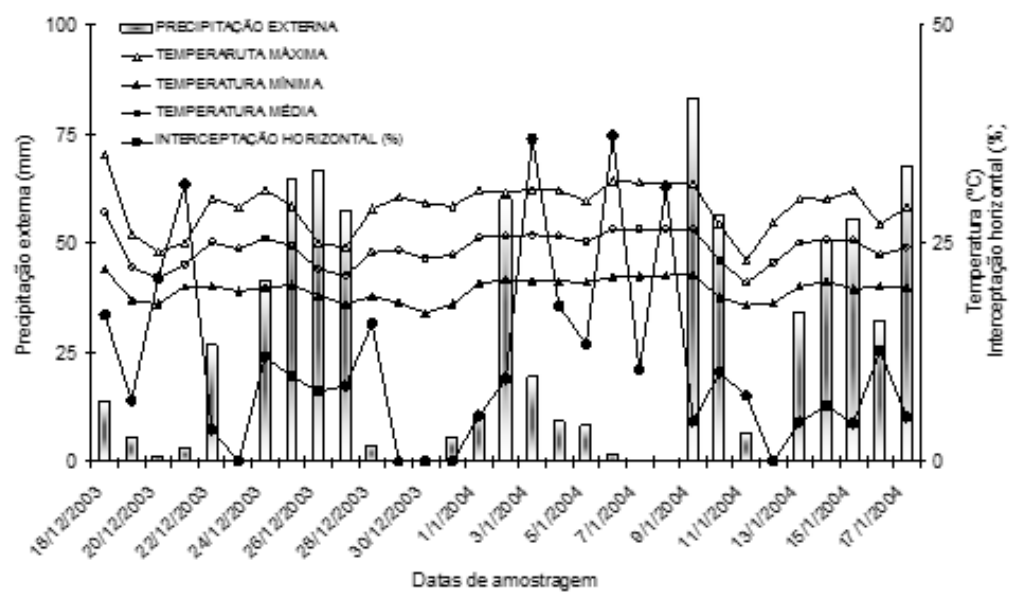

FIGURA 2: (A) Precipitação total, precipitação externa e interceptação horizontal, em milímetros; (B) precipitação externa e interceptação horizontal em milímetros; (C) precipitação externa (eixo primário), temperaturas máxima, mínima e média em ${ }^{\circ} \mathrm{C}$ e valores de interceptação horizontal em percentagem (eixo secundário).

FIGURE 2: (A) Total precipitation, external precipitation and horizontal interception, in millimeters; (B) external precipitation and horizontal interception, in millimeters; (C) external precipitation (primary axis), Minimum, medium and Maximum temperatures in ${ }^{\circ} \mathrm{C}$ and horizontal interception values in percentage (secondary axis). 
(A)

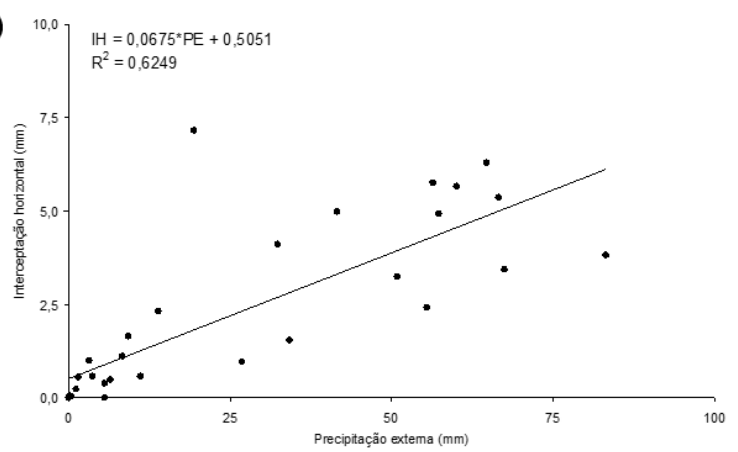

(B)

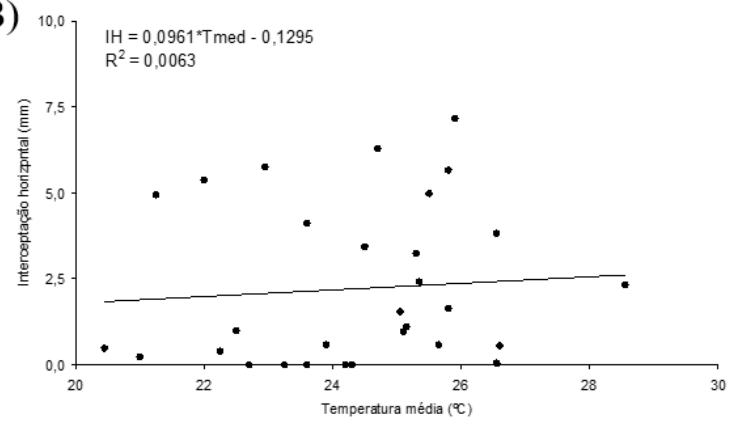

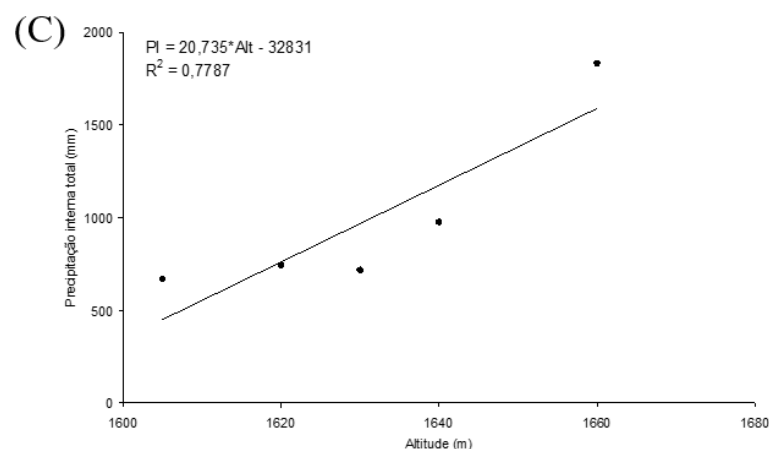

FIGURA 3: Regressão linear entre (A) interceptação horizontal e precipitação externa (B) interceptação horizontal e temperatura média e (C) precipitação interna e altitude.

FIGURE 3: Linear regression between (A) horizontal interception and external precipitation, (B) horizontal interception and mean temperature and $(\mathrm{C})$ internal precipitation and altitude.

$1,2,3,4$ e 5, respectivamente. Isso demonstra que houve, em diversos dias nas diferentes altitudes, maior precipitação interna que externa.

Nos dias em que não houve precipitação pluviométrica, a altitude, possivelmente, auxiliou na diminuição da temperatura durante a noite, reduzindo a capacidade de retenção de vapor d'água pela atmosfera, ou seja, o ar ficou saturado e a água no estado de vapor retornou ao estado líquido na forma de orvalho. Aliado a isso, possivelmente, a alta umidade das massas de ar incidentes na região também podem ter favorecido os valores elevados de condensação na superfície.

O fenômeno da interceptação pela copa, inevitável em qualquer ecossistema florestal, como discutido anteriormente, e quantificada como interceptação horizontal (IH), foi o principal responsável, ou fator indicativo, pelos valores de precipitação interna, encontrados (NIMER, 1979).

A análise estatística mostrou que PL1, PL2, PL3 e P, são iguais, estatisticamente e diferentes do PL4 e PL5, no nível de 1\% de probabilidade.

Verificou-se resultado distinto referente à precipitação interna e interceptação horizontal. Essa diferença observada é decorrente da interferência de outros fatores, tais como: velocidade do vento, características da vegetação, intensidade de chuva, umidade do ar e intervalo entre chuvas. Segundo Singh (1987), essas diferenças mostram a influência particular de cada ecossistema, onde o tipo de vegetação, características climatológicas locais, no que diz respeito principalmente a velocidade $\mathrm{e}$ direção do vento, além da umidade relativa interfere diretamente no volume precipitado internamente.

$\mathrm{O}$ processo de interceptação horizontal apresentou-se significativo a $1 \%$ de probabilidade, com correlação entre a precipitação total e interceptação horizontal de 70,98\%. Assim a capacidade da floresta interceptar ventos úmidos funcionaria, no sentido de redistribuir mais lentamente a água da chuva interceptada em direção ao solo, tendo como consequência uma maior captação de água.

Os valores de interceptação horizontal (IH) somados ao longo do período geraram uma contribuição de $68,71 \mathrm{~mm}(8,74 \%$ da precipitação externa), ou seja, uma média de $2,22 \mathrm{~mm} /$ dia indicando que a IH possui forte influência na produção de água. A quantificação desse mecanismo é um importante indicador da interação dos 
(A)
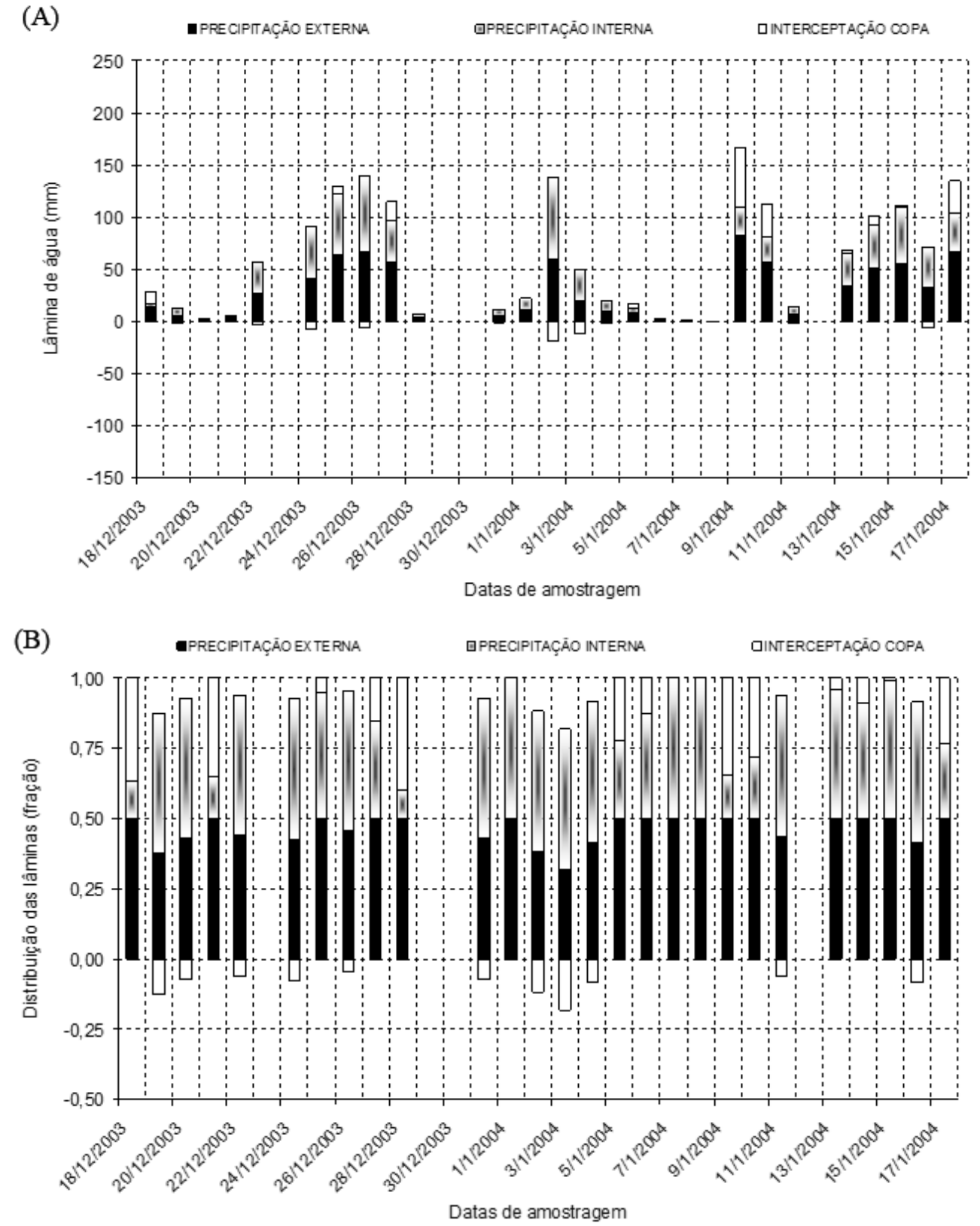

FIGURA 4: (A) Valores de precipitação externa, de precipitação interna e de interceptação de copa, em milímetros; (B) distribuição dos valores de precipitação externa, de precipitação interna e de interceptação de copa, em fração, no grupo de pluviômetros 1 (PL1).

FIGURE 4: (A) Values of external precipitation, internal precipitation and canopy interception, in millimeters; (B) Values of distribution of external precipitation, internal precipitation and canopy interception, in fraction, at the pluviometers group 1 (PL1).

processos climáticos e ecológicos, que influenciam de forma significativa o balanço hídrico.

A IH é um dos componentes do ciclo hidrológico, entretanto, esse fenômeno é percebido com mais intensidade em altitudes elevadas nas quais a temperatura, juntamente com a umidade do ar, propicia a condensação na superfície, como visto anteriormente.

\section{CONCLUSÕES}

A condensação do vapor d'água tem importância significativa, demonstrada pelos 

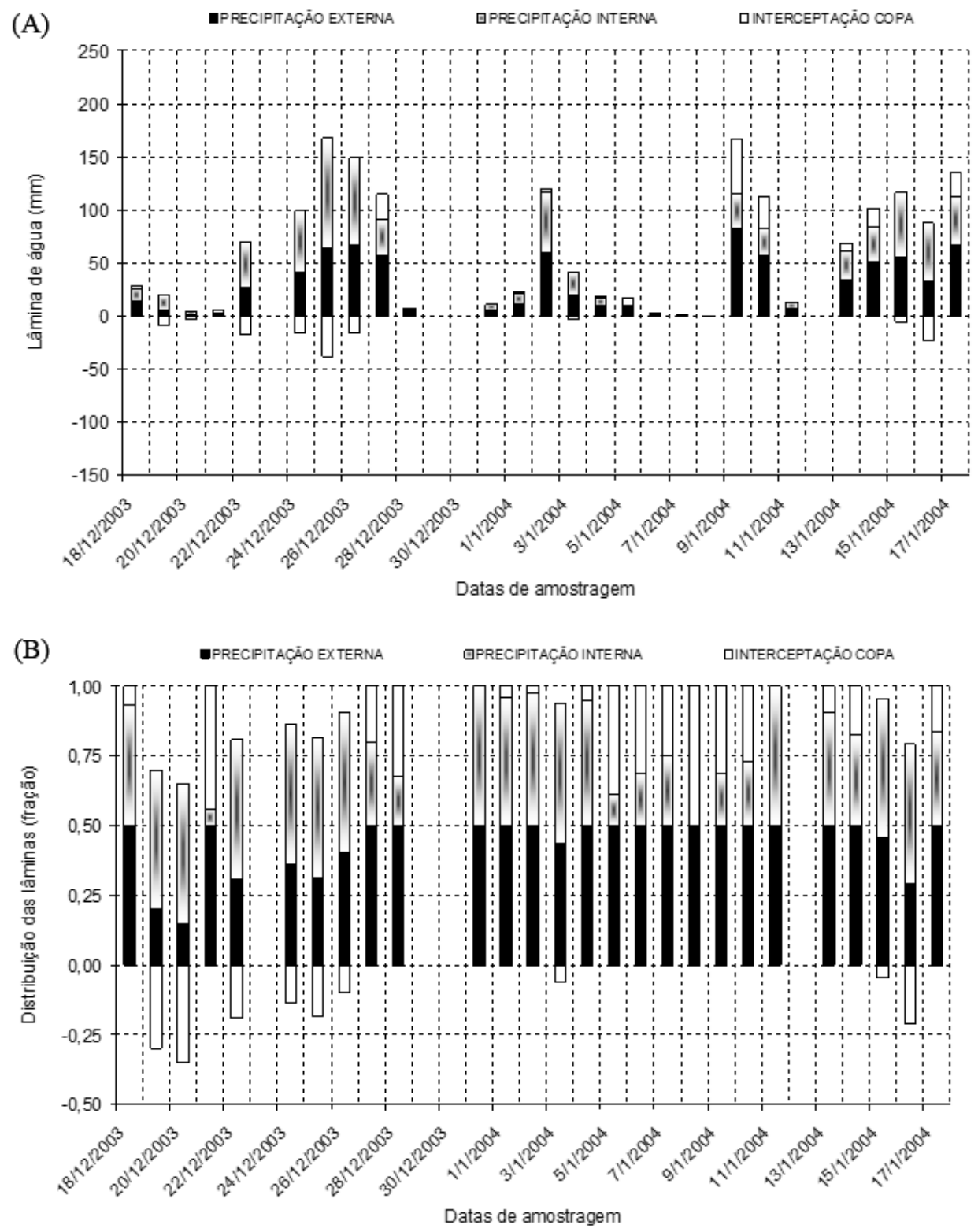

FIGURA 5: (A) Valores de precipitação externa, de precipitação interna e de interceptação de copa, em milímetros; (B) valores da distribuição dos valores de precipitação externa, de precipitação interna e de interceptação de copa, em fração, no grupo de pluviômetros 2 (PL2).

FIGURE 5: (A) Values of external precipitation, internal precipitation and canopy interception, in millimeters; (B) Values of distribution of external precipitation, internal precipitation and canopy interception, in fraction, in the pluviometer group 2 (PL2).

valores de interceptação de copa, precipitação interna e interceptação horizontal.

A chuva oculta deve ser levada em consideração e deve ser mais bem estudada para ajuste dos valores de entrada de água nos ecossistemas e para melhorar o ajuste de parâmetros de modelos hidrológicos, principalmente em regiões montanhosas.

Nas condições em que foi conduzido o presente estudo, a chuva oculta contribuiu positivamente, em média, com 2,22 milímetros diários para o balanço de água na região montanhosa da Serra do Mar, no Estado do Rio de Janeiro.

\section{REFERÊNCIAS BIBLIOGRÁFICAS}

ARCOVA, F. C. S.; CICCO, V.; ROCHA, P. A. B. Precipitação efetiva e interceptação das chuvas 

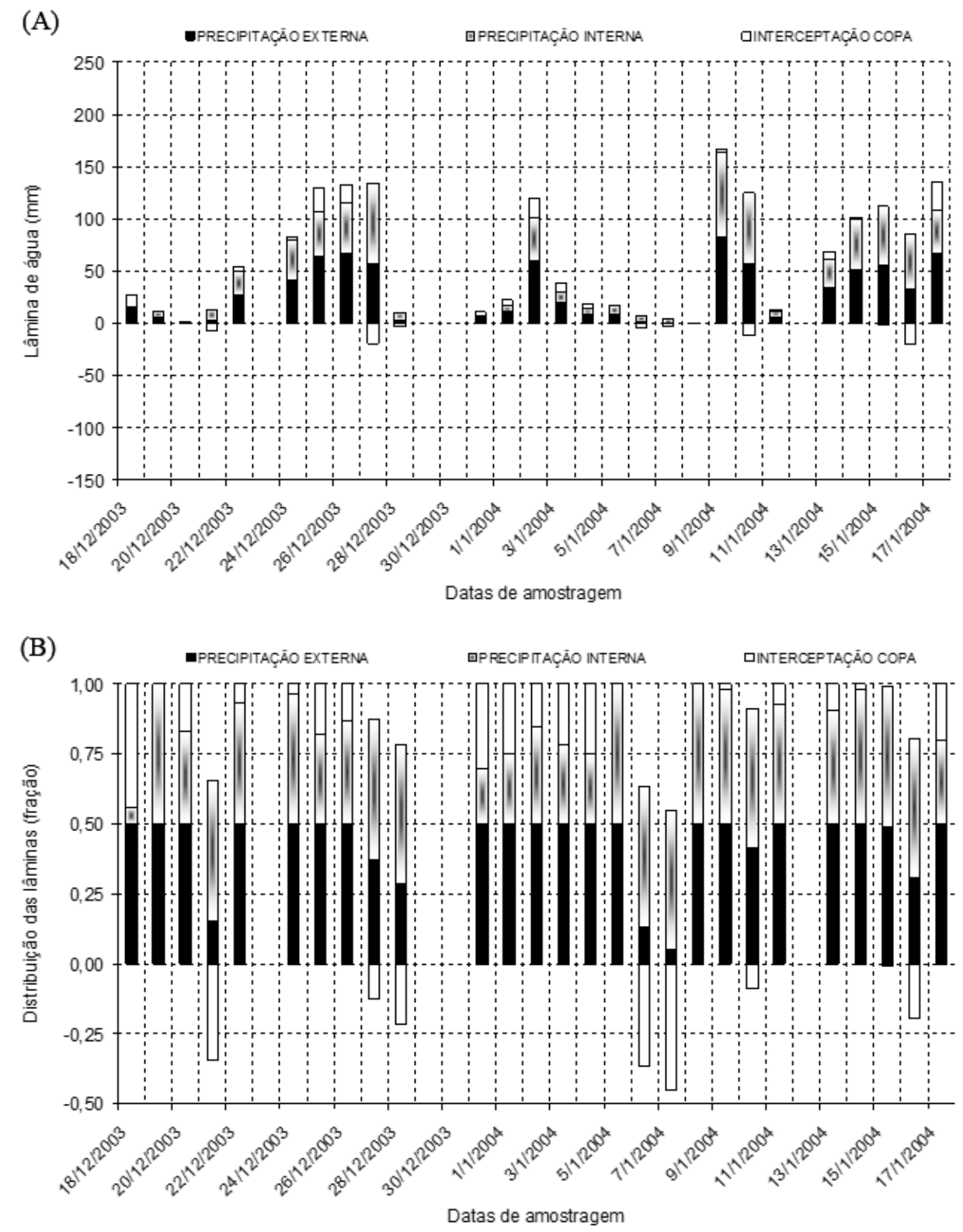

FIGURA 6: (A) Valores de precipitação externa, de precipitação interna e de interceptação de copa, em milímetros; (B) valores da distribuição dos valores de precipitação externa, de precipitação interna e de interceptação de copa, em fração, no grupo de pluviômetros 3 (PL3).

FIGURE 6: (A) Values of external precipitation, internal precipitation and canopy interception, in millimeters; (B) Values of distribution of external precipitation, internal precipitation and canopy interception, in fraction, in the pluviometer group 3 (PL3). 

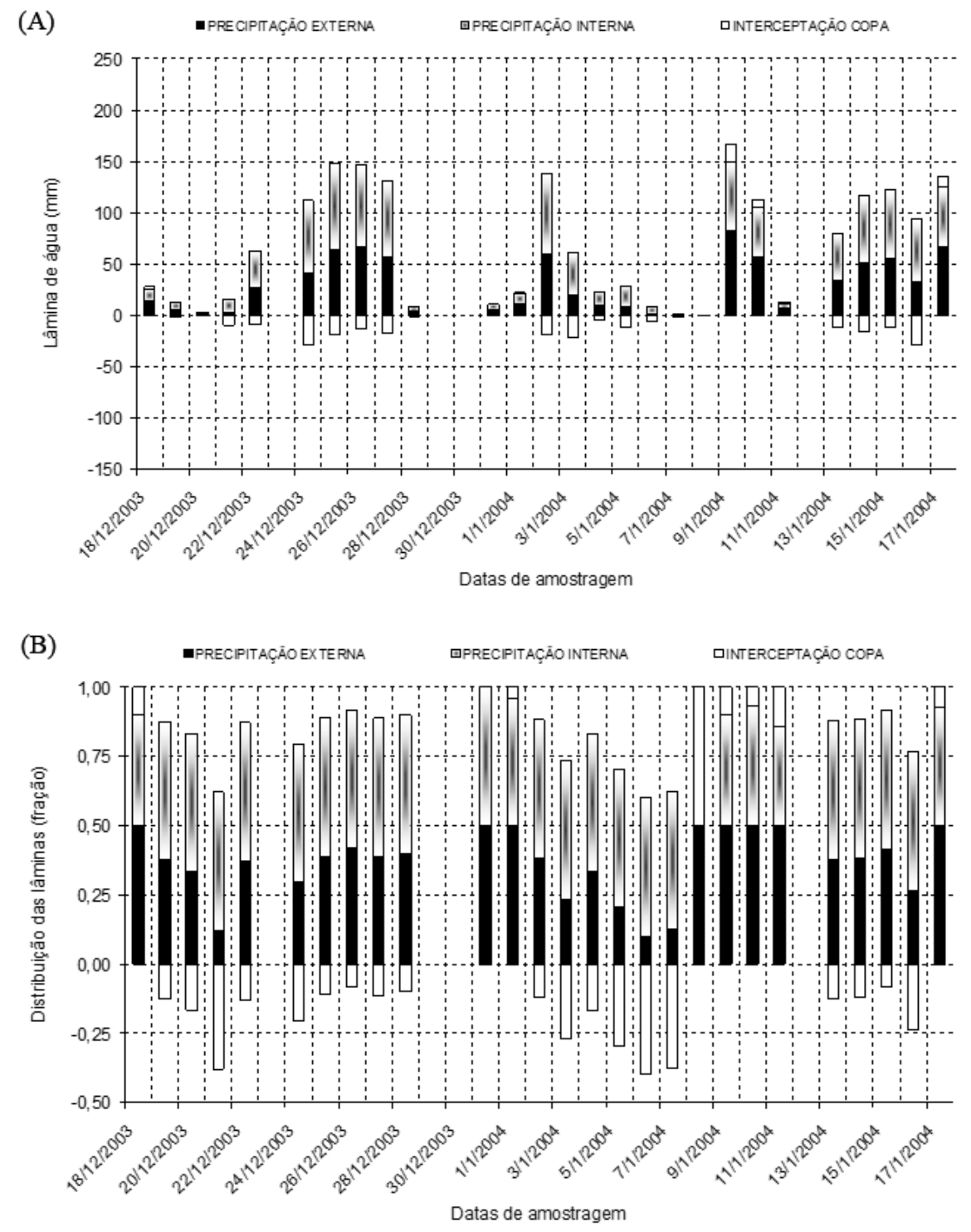

FIGURA 7: (A) Valores de precipitação externa, de precipitação interna e de interceptação de copa, em milímetros; (B) valores da distribuição dos valores de precipitação externa, de precipitação interna e de interceptação de copa, em fração, no grupo de pluviômetros 4 (PL4).

FIGURE 7: (A) Values of external precipitation, internal precipitation and canopy interception, in millimeters; (B) Values of distribution of external precipitation, internal precipitation and canopy interception, in fraction, in the pluviometer group 4 (PL4). 

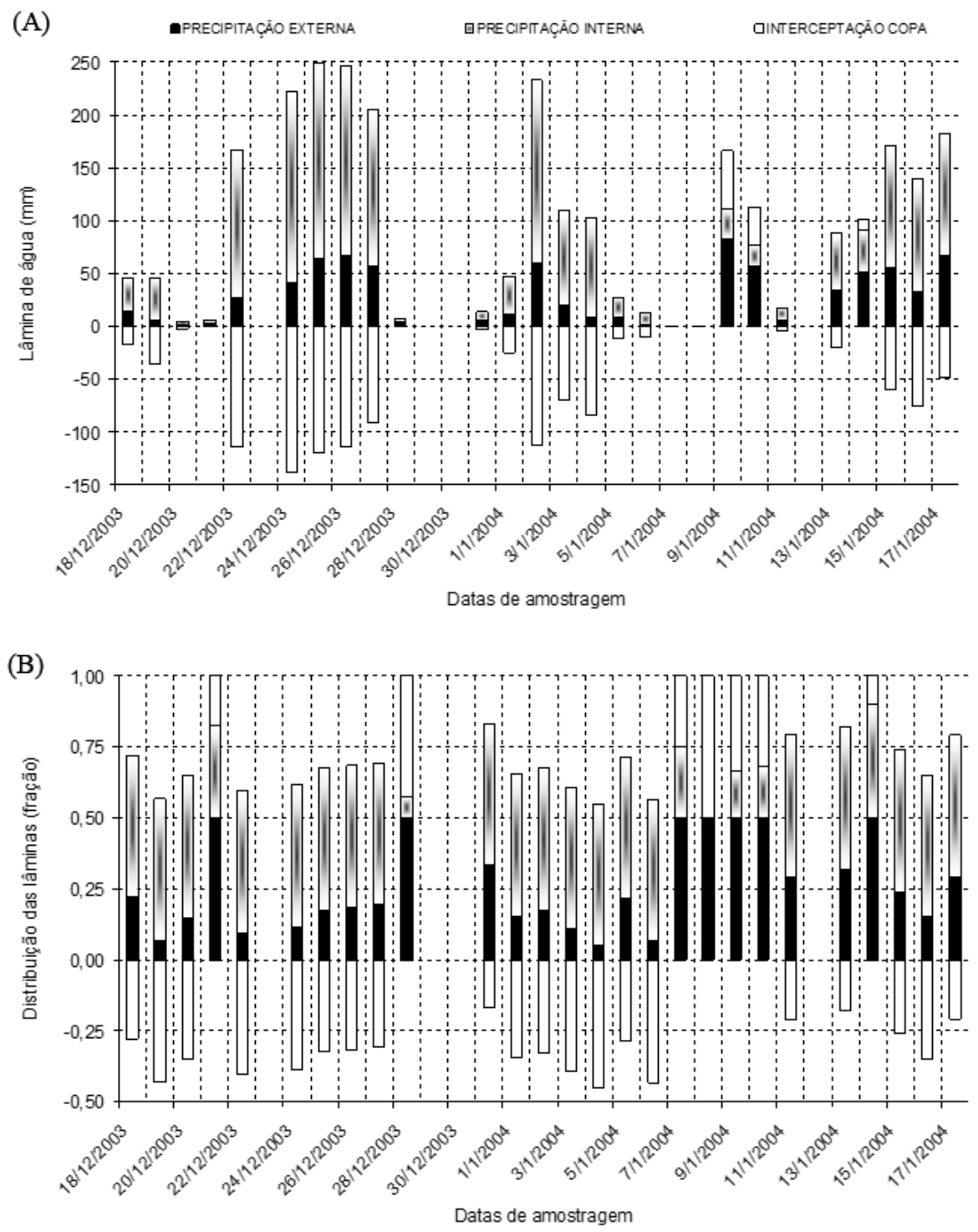

FIGURA 8: (A) Valores de precipitação externa, de precipitação interna e de interceptação de copa, em milímetros; (B) valores da distribuição dos valores de precipitação externa, de precipitação interna e de interceptação de copa, em fração, no grupo de pluviômetros 5 (PL5).

FIGURE 8: (A) Values of external precipitation, internal precipitation and canopy interception, in millimeters; (B) Values of distribution of external precipitation, internal precipitation and canopy interception, in fraction, in the pluviometer group 5 (PL5). 


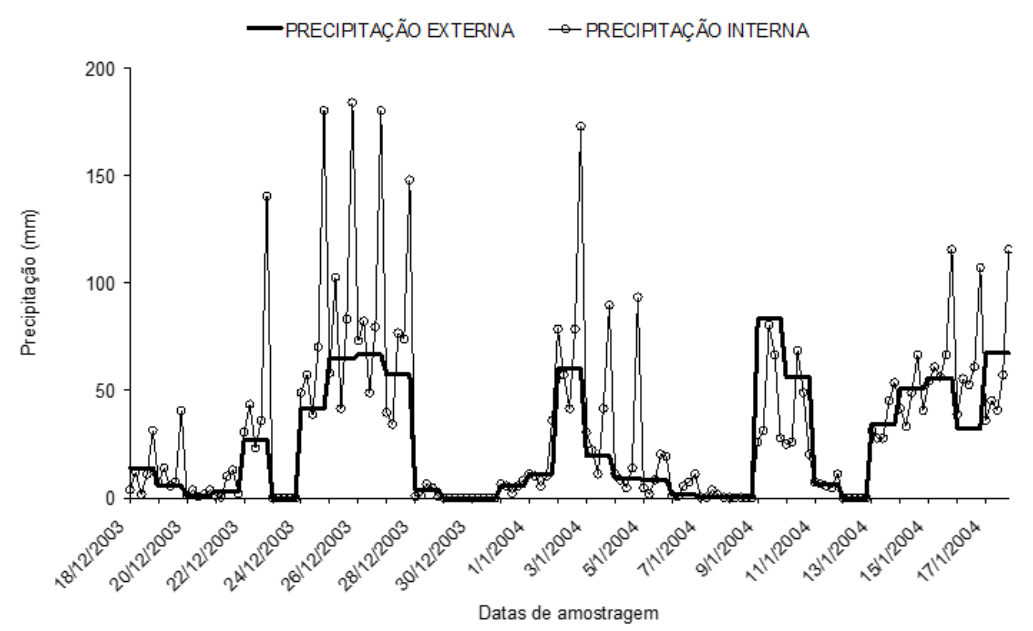

FIGURA 9: Valores de precipitação externa e de precipitação interna, em milímetros, ao longo do período experimental no local do ensaio.

FIGURE 9: Values of external precipitation, internal precipitation, along the experiment period in the experimental site.

TABELA 1: Valores e percentuais de precipitação externa (P); precipitação interna (PI), interceptação pela copa (IC) bem como os valores de $\mathrm{R}^{2}$ e coeficientes $a$ e $b$ nas diferentes áreas de amostragem (PL1, PL2, PL3, PL4 e PL5) localizadas nas diferentes altitudes.

TABLE 1: Values and percentage of external precipitation (P); Internal precipitation (PI), canopy interception (IC) so as $\mathrm{R}^{2}$ values, $a$ and $b$ coefficients at the different survey areas (PL1, PL2, PL3, PL4 and PL5) located at different altitudes.

\begin{tabular}{|c|c|c|c|c|c|c|}
\hline & \multicolumn{6}{|c|}{ Precipitação Interna (PI) } \\
\hline & $\mathrm{P}(\mathrm{mm})$ & PL1 (mm) & PL2 (mm) & PL3 (mm) & PL4 (mm) & PL5 (mm) \\
\hline ALTITUDE (m) & $1.560,0$ & $1.605,0$ & $1.620,0$ & $1.630,0$ & $1.640,0$ & $1.660,0$ \\
\hline $\begin{array}{l}\text { PRECIPITAÇÃO }\left(\mathrm{P}, \mathrm{PL}_{\mathrm{i}}\right) \\
\mathrm{mm}(\%)\end{array}$ & $\begin{array}{l}786,2 \\
(100)\end{array}$ & $\begin{array}{l}669,1 \\
(85,1)\end{array}$ & $\begin{array}{l}743,5 \\
(94,6)\end{array}$ & $\begin{array}{l}717,3 \\
(91,2)\end{array}$ & $\begin{array}{c}976,2 \\
(124,2)\end{array}$ & $\begin{array}{l}1.833,4 \\
(233,2)\end{array}$ \\
\hline $\begin{array}{l}\text { INTERCEPTAÇÃO (IC) } \\
\mathrm{mm}(\%)\end{array}$ & $0(0)$ & $\begin{array}{l}117,2 \\
(14,9)\end{array}$ & $\begin{array}{c}42,73 \\
(5,4)\end{array}$ & $\begin{array}{l}68,9 \\
(8,8)\end{array}$ & $\begin{array}{l}-190,0 \\
(-24,2)\end{array}$ & $\begin{array}{c}-1.047,0 \\
(-133,2)\end{array}$ \\
\hline $\mathrm{R}^{2}$ & - & $72,11 *$ & $67,58 *$ & $85,56 *$ & $88,17 *$ & $48,71 *$ \\
\hline$A$ & - & $2,71 \mathrm{~ns}$ & $2,64 \mathrm{~ns}$ & $0,74 \mathrm{~ns}$ & $4,31 \mathrm{~ns}$ & $16,12 \mathrm{~ns}$ \\
\hline$B$ & - & $0,74 *$ & $0,84 *$ & $0,88 *$ & $1,07 *$ & $1,7 *$ \\
\hline
\end{tabular}

Em que: * significativos a $1 \%$ de probabilidade; ns - não significativo; $\mathrm{P}$ - Precipitação externa. PI - Precipitação interna. IC - Interceptação de chuva pela copa. $\mathrm{R}^{2}$ - Coeficiente de determinação. $a$ e $b$-constantes da equação da reta ( $a$ é o coeficiente angular da reta e $b$ onde a reta cruza o eixo y). $\mathrm{PL}_{\mathrm{i}}-$ Áreas de amostragens em diferentes altitudes.

por Floresta de Mata Atlântica em uma microbacia experimental em Cunha, São Paulo. Revista Árvore, Viçosa, MG, v. 27, n. 2, p. 257-262, 2003.

ARONICA, G.; CANNAROZZO, M. Studying the hydrological response of urban catchments using a semi-distributed linear non-linear model. Journal of Hydrology, Amsterdam, v. 238, p. 35-43, 2000. CHEN, J. M.; CHEN, X.; JU, W. Distributed hydrological model for mapping evapotranspiration using remote sensing inputs. Journal of Hydrology, Amsterdam, v. 305, p. 15-39, 2005.

GANDOLFI, S.; JOLY, C. A.; RODRIGUES, R. R. Permeability-impermeability: canopy trees as biodiversity filters. Scientia Agrícola, Piracicaba, SP, v. 64, p. 433-438, 2007.

GIGLIO, J. N.; KOBIYAMA, M. Interceptação da chuva: uma revisão com ênfase no monitoramento em florestas brasileiras. Revista Brasileira de 
Recursos Hídricos, Porto Alegre, v. 18, n. 2, p. 297-317, 2013.

HUBER, A. M.; OYARZÚN, C. E. Redistribución de las precipitaciones en un bosque simpre verde del sur de Chile. Turrialba: Revista Interamericana de Ciências Agrícolas, San Jose, v. 42, p. 192-199, 1992.

IBGE. Manual técnico da vegetação brasileira. Rio de Janeiro: IBGE, 1992. $91 \mathrm{p}$.

JOHNSON, R. G. The interception, throughfall and stemflow im a forest in Highland Scotland and the comparison with other upland forests in U.K. Journal of Hydrology, Amsterdam, v. 118, p. 281287, 1990.

LIMA, H. C.; GUEDES-BRUNI，R. R. Serra de Macaé de Cima: diversidade Florística e Conservação em Mata Atlântica. Rio de Janeiro: Jardim Botânico do Rio de Janeiro, 1997. 346 p.

LIMA, W. P. Princípios de hidrologia florestal para o manejo de bacias Hidrográficas. Piracicaba: Escola Superior de Agricultura "Luiz de Queiroz”, Universidade de São Paulo, 1986. 242 p. LLOYD, C. R.; GASH, J.H.C.; SHUTTLEWORTH, $\mathrm{W}$. J. The measurement and modelling of rainfall interception by amazonian rain forest. Agricultural and Forest Meteorology, Amsterdam, v. 43, p. 277-294, 1988 .

MOLCHANOV, A. A. Hidrologia Florestal. Lisboa: Fundação Calouste Gulbenkian, 1971. $419 \mathrm{p}$.

NALON, M. A.; VELLARDI, A. C. V. Estudo do balanço hídrico nas escarpas da serra do mar, região de Cubatão, SP. Revista do Instituto Florestal, São Paulo, v. 5, n. 1, p. 39-58, 1993.

NIMER, E. Climatologia do Brasil. Rio de Janeiro: IBGE, 1979. $421 \mathrm{p}$.

OTTONI NETTO, T. B. Fundamentos de engenharia ambiental com ênfase em recursos hídricos. Perenização e regularização fluvial. Rio de Janeiro: Apostila da UFRJ, 1993. 232 p. PRIMAVESI, O.; PRIMAVESI, A. C. Fundamentos ecológicos para o manejo efetivo do ambiente rural nos trópicos: educação ambiental e produtividade com qualidade ambiental. São Carlos: Embrapa Pecuária Sudeste, 2003. 84 p. (Embrapa Pecuária Sudeste. Documentos, 33).

SANSEVERO J. B. B. et al. Natural Regeneration in Plantations of Native Trees in Lowland Brazilian Forest: Community, Structure, Diversity and Dispersal Sydromes. Restoration Ecology, Malden, v. 19, n. 3, p. 379-389, 2011.

SCCOTI, M. S. V. et al. Mecanismos de regeneração natural em remanescente de floresta estacional decidual. Ciência Florestal, Santa Maria, v. 21, n. 3, p. 459-472, 2011.

SHINZATO, E. T. et al. Escoamento pelo tronco em diferentes povoamentos florestais na Floresta Nacional de Ipanema em Iperó, Brasil. Scientia Forestalis, Piracicaba, SP, v. 39, n. 92, p. 395-402, 2011.

SINGH, R. P. Rainfall interception by Pinus wallichiana plantation in temperate region of Himachal Pradesh, India. Indian Forester, Gehara Dun, v. 104, p. 559-566, 1987. 